\title{
ASSESSMENT OF THE AWARENESS AND SAFETY PRACTICES IN MITIGATING HAZARDS OF SILICA DUST EXPOSURE AMONG CONSTRUCTION WORKERS
}

\author{
Engr. Jeferd E. Saong, Abigail L. Babaran, Glenn Dale A. Balaho \\ School of Engineering and Architecture \\ University of Baguio, Baguio City, Philippines
}

\begin{abstract}
Construction sites generate high levels of dust typically from concrete, silica, asbestos, cement, wood, stone, and sand. Workers who are exposed to the said environment are faced with the risk of inhaling particulate materials that might lead to adverse respiratory problems. The lack of publication on the awareness of construction workers on the risk associated with silica dust exposure was the basis of the study. This study assessed the level of awareness of construction workers on the risk associated with silica dust exposure and the safety practices to minimize it. Purposive sampling was used in the selection of 65 respondents from different construction sites located in Baguio City, Philippines. A survey questionnaire containing four point Likert scales were used to determine the level of awareness on the health effects, mode of transmission, and sources of silica dust. The study further assessed the level of safety practices in mitigating the effects of silica dust exposure. The respondents were moderately aware $(M=2.52)$ of the health effects, moderately aware $(M=2.69)$ of the mode of transmission, and moderately aware $(M=3.08)$ of the sources of silica dust. The results further showed that the respondents moderately practiced $(M=2.84)$ activities to mitigate the health effects of silica dust exposure and moderately practiced $(M=3.17)$ the use of personal protective equipment in the construction site. The results suggest that construction workers must be made more aware of the health effects of silica dust exposure and, mitigation activities and utilization of personal protective equipment must be strictly imposed in the construction
\end{abstract}

site.

Keywords: Silica dust exposure, silica dust exposure awareness, safety practices

\section{INTRODUCTION}

All construction sites generate a high level of dust typically from concrete, silica, asbestos, cement, and wood, stone and sand. Workers who are exposed to dusty environment faced the risk of inhaling particulate materials [1] that might lead to adverse respiratory effects [2]. The high-risk occupations for these conditions include those in the mining [3], rock grinding and crushing, sandblasting, ceramic, construction and manufacturing industries. According to the Occupational Safety and Health Administration (OSHA), crystalline silica is one of the most abundant material in earth's crust. It is mostly found in sand, rocks and minerals and commonly used in construction industry. Around 2.2 million workers are exposed to respirable crystalline silica in their workplaces and about 1.85 million of these are in construction industry. Mariammal, Jaisheeba and Sornaraj (2012) conducted a study which assessed the respiratory status of both construction and sanitary workers at Thoothukudi [4]. A standardized questionnaire was distributed to 249 construction and sanitary workers. Out of 249 workers, only 92 of them has healthy respiratory status and the rest was discovered having lung complications. The study of Mariammal et. al also stated that activities associated with dust exposure are dry dust sweeping, vehicular movements, physical activities and construction activities (i.e., drilling, cutting, grinding or chipping of the objects). 
International Journal of Engineering Applied Sciences and Technology, 2021

Vol. 5, Issue 10, ISSN No. 2455-2143, Pages 60-65

Published Online February 2021 in IJEAST (http://www.ijeast.com)

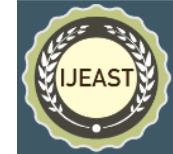

Materials like cement and asbestos produces tiny respirable dust particles that are being inhaled by the workers and might lead to respiratory problems such as coughing, sneezing, throat infection, lung cancer and other types of cancer [5]-[6]. In addition, silica dust exposure could also cause kidney disease, chronic obstructive pulmonary disease and may increase the risks of asthma, tuberculosis, renal heart disease, rare skin and tissue disease [7].

Occupational Safety and Health Administration (OSHA) set new standard rule for a permissible exposure limit of 25 milligrams of silica dust per cubic meter of air, averaged over an eight-hour per day and provided three methods for the employers to protect the employees which are the table method, objective data and air monitoring program. OSHA also issued a mitigating control to resist silica dust exposure and requires the employers to help the construction workers in preventing the impact of silica dust (especially to their health and require them to use engineering controls such as water sprays or local exhaust, respirator and personal protective equipment [8]. Safety managers have to observe the construction workers in able check if they comply with the rules of OSHA, while the program administrators have to see if the construction workers follow the correct procedure of using equipment like a respirator, dust mask and personal protective equipment. All officers have the power to correct if the workers are violating the required silica regulation which prevents them from silica dust exposure. The methods provided by OSHA can be used globally. Highly developed countries like United States of America, Canada or Australia are using an advanced engineering controls and housekeeping such as ventilation, dust containment, and health monitoring systems. According to Workplace Health and Safety Queensland (2013), one problem in preventing the exposure from clouds of dust containing respirable silica is the lack of perception about the risk it could give. Also, respirable dust is essentially invisible through normal lighting conditions. From their intervention, in non-tunneling construction and related works, the dust is controlled by occasional use of Respiratory Protective Equipment (RPE) and by suppression of water which was applied in usefully in outdoor operations. The overall use of the respirator in the non-tunneling workplaces is low with some workers used a disposable respirator and one using proper RPE due to excessive dust concentration.
In the Philippines, materials containing silica dust are found in asbestos which is commonly used for the manufacture of construction materials, friction materials and gaskets. More than 77 companies are using asbestos for the finished materials in the Philippines and it is estimated that about 5,298 and 30,000 workers are being exposed and affected directly and indirectly to asbestos but the exact number of workers with silica and coal dust exposure in the Philippines has not yet been established [9]. According to the Department of Labor and Employment (DOLE, 2016), employers administer training and education to the workers about risk assessment and control along with a health monitoring system, it is currently undiscovered if there are literatures concerning surveillance system for respirable crystalline silica but there are similar case study like asbestos in which it contains a small amount of crystalline silica. The Department of Labor and Employment (DOLE) and the Department of Public Works and Highways (DPWH) have signed a memorandum of agreement for the improvement of a process cycle time for the safety and health of the construction workers and employers and also to strengthen the connection in promoting welfare and growth of the construction industries that will help in reducing and eliminating the incidents and accidents happened during construction activities. In the study conducted by Grandillos et al (2020), the surface and underground small scale gold mining industry in the Philippine designate officer to check the concentration of respirable crystalline silica fraction inhaled by the mine workers especially when they are exposed to the surface and underground mining. This will help them to mitigate silica exposure and prevent certain health problems [10]. According to the Philippine Statistics Authority (PSA, 2018), there are effective preventive and control measures against work safety and health hazards. Thus includes posting of safety signage or warning signs, providing emergency response and preparation activities, imposing smoke free workplace, appointment of safety or health officers and first aid personnel who will conduct regular inspections and maintenance of equipment and will require workers and employees to attend training and seminars about workplace. The study of Johncy et al (2011) shows that the exposure from high concentration of dust contains crystalline silica will affect the lung function of the construction workers in the site. 


\section{International Journal of Engineering Applied Sciences and Technology, 2021 \\ Vol. 5, Issue 10, ISSN No. 2455-2143, Pages 60-65 \\ Published Online February 2021 in IJEAST (http://www.ijeast.com)}

This study assessed the level of awareness of construction workers on the risk associated with silica dust exposure and their safety practices to minimize the risk. It specifically determined the level of awareness on the health effects, mode of transmission, and sources of silica dust exposure. The study further assessed the level of safety practices in mitigating the effects of silica dust exposure.

\section{METHODOLOGY}

The descriptive-survey design was utilized in the study to describe the awareness and safety practices of construction workers in relation to silica dust exposure. The indicators for the survey were based on the Occupational Health and Safety Administration handbook (OSHA, 2017).

The study was conducted in Baguio City, Philippines with focused on on-going construction sites during the $2^{\text {nd }}$ semester of school year 2018-19. The study involved 65 construction workers as respondents. Purposive sampling was employed for the selection of construction sites and respondents exposed to silica dust during construction.

A survey questionnaire was used to gather data from the respondents. The questionnaire included construction worker's experiences, knowledge related to silica dust, and protective measures to silica dust exposure. The questionnaire used a 4-point Likert scale with from 4 (very much aware/very much practiced) down to 1 (not aware/not practiced).

The researchers conducted the gathering of data at identified construction sites through approval of assigned officers and willingness of the construction workers. The questionnaires were administered during the break of the construction workers. The researchers explained and discussed the purpose of the study, briefed the construction workers on the questionnaire, distributed the questionnaire, allowed the respondents to answer the questionnaire on their free will, and collected the questionnaire.

Weighted mean was used to analyze the data gathered from the questionnaires for the level of awareness and practices of the construction workers using:

$$
\text { 3.26-4.00 very much aware/ }
$$

very much practiced

2.51-3.25

moderately practiced

$$
1.76-2.50
$$

slightly practiced

$$
\text { 1.00-1.75 not aware/ not }
$$

practiced

The researchers informed the respondents of the study on the objectives of the study. In the data gathering process, the researchers sought permission from the construction site supervisors, the respondents were free to decline their participation and were not forced in their participation. Anonymity of construction sites and construction workers were observed in the study. Confidentiality of construction sites and construction workers were observed by not disclosing the information of the respondents. The respondents were informed that the result of the study will be made public through a research presentation.

\section{RESULTS AND DISCUSSIONS}

\section{Level of Awareness on the Risks Associated with Silica Dust Exposure}

The level of awareness of the respondents to the contribution of silica dust exposure is shown in Table 1. The respondents are moderately aware $(\mathrm{M}=2.52, \mathrm{SD}=0.98)$ on the contribution of silica dust to respiratory problems. It is evident that the respondents were very much aware that exposure to silica dust contributes to coughing $(\mathrm{M}=3.36, \mathrm{SD}=0.79)$ but are slightly aware that it contributes to fever $(\mathrm{M}=1.97$, $\mathrm{SD}=1.04)$, chest pain $(\mathrm{M}=2.44, \quad \mathrm{SD}=1.14)$, respiratory failure $(\mathrm{M}=2.39, \mathrm{SD}=1.06)$, loss of appetite $(\mathrm{M}=2.19, \mathrm{SD}=0.99)$, and throat infection $(\mathrm{M}=2.22, \mathrm{SD}=0.95)$. Chest foundation (2018) stated that coughing contributed by exposure to silica by inhalation may lead to silicosis, and silica dust exposure could lead to sneezing, throat infection, and coughing that may increase the risk of other respiratory problems. Barnes et al (2019) stressed that respirable silica dust can scar tissues of the lungs that can lead to cough, fever, loss of appetite, chest pain, and respiratory failure [12]. The results affirm that exposure to silica dust may lead to lung problems with noticeable symptoms such as cough and fever.

Table 1. Level of awareness on the health effects of silica dust exposure

\begin{tabular}{clll}
\hline High exposure to silica dust contributes to & Mean, M & $\begin{array}{l}\text { Standard } \\
\text { Deviation, SD }\end{array}$ & $\begin{array}{l}\text { Descriptive } \\
\text { Interpretation }\end{array}$ \\
\hline 1. Fever & 1.97 & 1.04 & Slightly aware
\end{tabular}


International Journal of Engineering Applied Sciences and Technology, 2021

Vol. 5, Issue 10, ISSN No. 2455-2143, Pages 60-65

Published Online February 2021 in IJEAST (http://www.ijeast.com)

2. Sneezing

3. Fatigue

4. Coughing

5. Chest pain

6. Respiratory failure

7. Loss of appetite

8. Throat infection

$\begin{array}{ll}2.83 & 0.96 \\ 2.78 & 0.95 \\ 3.36 & 0.79 \\ 2.44 & 1.14 \\ 2.39 & 1.06 \\ 2.19 & 0.99 \\ 2.22 & 0.95 \\ \mathbf{2 . 5 2} & \mathbf{0 . 9 8}\end{array}$

Moderately aware Moderately aware Very much aware Slightly aware Slightly aware Slightly aware Slightly aware Moderately aware

Table 2 shows the level of awareness of the respondents on the mode transmission of silica dust to the human body. As gleaned in Table 2, respondents are moderately aware $(\mathrm{M}=2.69, \mathrm{SD}=0.95)$ of the possible mode of transmissions of silica dust to the respiratory system. The respondents are very much aware that inhalation of silica dust $(M=3.28, S D=0.97)$; slightly aware that swallowing $(M=2.28, S D=1.03)$ and skin contact $(M=2.47, S D=0.91)$ were sources of silica dust exposure. Barnes et al (2019) emphasized that the primary source of silica dust is through inhalation from materials such as concrete, bricks, and other construction materials. Johncy, et al, (2011) stressed that workers in dusty environment are at risk of inhaling particulate materials inhaled particles will cause damage to the lungs. The results uphold that silica dust is dominantly transmitted through inhalation.

Table 2. Level of awareness on mode of transmission of silica dust

\begin{tabular}{cllll}
\multicolumn{2}{l}{ Transmission of silica dust can be through } & Mean, M & $\begin{array}{l}\text { Standard } \\
\text { Deviation, SD }\end{array}$ & $\begin{array}{l}\text { Descriptive } \\
\text { Interpretation }\end{array}$ \\
\hline 1. & Inhalation & 3.28 & 0.97 & Very much aware \\
2. Skin contact & 2.47 & 0.91 & Slightly aware \\
3. & Eye contact & 2.72 & 0.88 & Moderately aware \\
4. Swallowing & 2.28 & 1.03 & Slightly aware \\
& & $\mathbf{2 . 6 9}$ & $\mathbf{0 . 9 5}$ & Moderately aware \\
\hline
\end{tabular}

The sources of silica dust are shown in Table 3. As indicated in Table 3, the respondents are moderately aware $(M=3.08, S D=0.84)$ on the sources of exposure to silica dust. The respondents are very much aware that rock crushing $(\mathrm{M}=3.28, \mathrm{SD}=0.80)$ is a source of exposure to silica dust and moderately aware on the other indicators. Johncy, et al, (2011) stressed that workers in crushing and construction occupations face the risk of exposure to silica dust. Mariammal et al, (2012) and Flanagan et al (2003) [11] stated that construction activities such as drilling, cutting, grinding, cement mixing, and chipping are associated to silica dust exposure. This implies that the respondents are familiar to silica dust exposure in construction activities.

Table 3. Level of awareness on the sources of silica dust

\begin{tabular}{cllll}
\hline Sources of silica dust include & Mean, M & $\begin{array}{l}\text { Standard } \\
\text { Deviation, SD }\end{array}$ & $\begin{array}{l}\text { Descriptive } \\
\text { Interpretation }\end{array}$ \\
\hline 1. Drilling & 2.86 & 1.06 & Moderately aware \\
2. Plastering & 3.08 & 0.83 & Moderately aware \\
3. Demolition & 2.78 & 0.97 & Moderately aware \\
4. Rock crushing & 3.28 & 0.80 & Very much aware \\
5. Power sanding & 3.25 & 0.79 & Moderately aware \\
6. Concrete chipping & 3.08 & 0.83 & Moderately aware \\
7. Concrete cutting & 3.06 & 0.70 & Moderately aware \\
8. Mixing of cement & 3.25 & 0.76 & Moderately aware \\
& & $\mathbf{0 . 8 4}$ & Moderately aware \\
\hline
\end{tabular}

\section{Safety Practices in Mitigating Silica Dust Exposure}

The practices in addressing silica dust exposure is shown in Table 4. It is shown that the respondents are moderately practicing $(\mathrm{M}=2.84, \mathrm{SD}=0.96)$ the indicators to mitigate exposure to silica dust. The respondents are moderately practices sweeping silica dust with water $(\mathrm{M}=3.22, \mathrm{SD}=0.97)$ and adequate ventilation $(\mathrm{M}=3.19, \mathrm{SD}=0.88)$ but slightly practices drilling activities with water $(\mathrm{M}=2.50, \mathrm{SD}=1.04)$ and sawing concrete with water $(2.44, \mathrm{SD}=0.96)$ to avert silica dust exposure. The Occupational Safety and Health Authority (2017), issued that wet methods are effective to resist silica dust exposure. This suggests 


\section{International Journal of Engineering Applied Sciences and Technology, 2021 \\ Vol. 5, Issue 10, ISSN No. 2455-2143, Pages 60-65 \\ Published Online February 2021 in IJEAST (http://www.ijeast.com)}

that sweeping silica dust with water and adequate ventilation minimizes dust concentration in construction activities.

Table 4. Practices in addressing silica dust exposure

\begin{tabular}{cllll}
\hline Indicators & Mean, M & $\begin{array}{l}\text { Standard } \\
\text { Deviation, } \\
\text { SD }\end{array}$ & Descriptive Interpretation \\
\hline 1. Sweeping silica dust with water & 3.22 & 0.97 & Moderately practiced \\
2. Drilling activities with water & 2.50 & 1.04 & Slightly practiced \\
3. Sawing concrete with water & 2.44 & 0.96 & Slightly practiced \\
4. Adequate ventilation & 3.19 & 0.88 & Moderately practiced \\
& & $\mathbf{0 . 9 6}$ & Moderately practiced \\
\hline
\end{tabular}

Table 5 shows the utilization of personal protective equipment to mitigate silica dust exposure. As gleaned, the respondents are moderately practicing $(\mathrm{M}=3.17, \mathrm{SD}=0.92)$ the use of protective equipment to mitigate silica dust exposure. The very much practiced use of protective equipment for silica dust mitigation is the use of head protection $(\mathrm{M}=3.28, \mathrm{SD}=0.90$ while the rest of the practice indicators are moderately practiced. The occupational safety and health authority (2017) required the use of protective equipment in construction activities. Stewart (2019) stressed that protective equipment such as respirator, dust mask, and personal protective equipment prevents exposure to silica dust exposure. This implies that the respondents need familiarity to the personal protective equipment required in dealing with silica dust.

Table 5. Utilization of personal protective equipment for silica dust exposure

\begin{tabular}{|c|c|c|c|c|}
\hline $\begin{array}{l}\text { In addressing silica dus } \\
\text { following are used }\end{array}$ & exposure, the & Mean, M & $\begin{array}{l}\text { Standard } \\
\text { Deviation, SD }\end{array}$ & $\begin{array}{l}\text { Descriptive } \\
\text { Interpretation }\end{array}$ \\
\hline 1. Face protection & & 3.06 & 1.00 & Moderately practiced \\
\hline Head protection & & 3.28 & 0.90 & Very much practiced \\
\hline Skin protection & & 3.19 & 0.91 & Moderately practiced \\
\hline Clothing & & 3.25 & 0.86 & Moderately practiced \\
\hline eye protection & & 3.00 & 0.91 & Moderately practiced \\
\hline Foot wear & & 3.25 & 0.92 & Very much practiced \\
\hline & Over-all & 3.17 & 0.92 & Moderately practiced \\
\hline
\end{tabular}

\section{CONCLUSION AND RECOMMENDATION}

The results imply that construction workers are at high health risk due to the moderate level of awareness on risk factors and moderate level of safety practices associated with silica dust exposure. This calls for appropriate actions or programs from concerned government agencies and construction companies to protect the wellbeing of the construction workers. The results further suggest that construction workers must be made more aware of the health effects of silica dust exposure through seminars and trainings, and mitigation activities and utilization of personal protective equipment must be strictly imposed in the construction site.

\section{REFERENCES}

[1] Sauveé, J. Beuadry, C., Bégin, D., Dion, C., Gérin, M., Lavoué, J. (2012). Silica exposure during construction activities: Statistical modelling of task-based measurements from the literature. The annals of occupational hygience, 54(4) (pp 432-443)

[2] Johncy, S.S., Ajay K. T., Dhanyakumar, G., Raj, N.P., Samuel, T.V. (2011). Dust exposure and lung function impairment in construction workers. Journal of Physiological and Biomedical Sciences, 24(1) (pp 9-13)

[3] Gottesfeld, P., Andrew, D., Dalhoff, J. (2015). Silica exposures in artisanal small-scale gold mining in Tanzania and implications for tuberculosis prevention. Journal of occupational and environmental hygiene, 12(9) (pp 647-653)

[4] Mariammal, T., Jaisheeba, A.A., Sornaraj, R. (2012). Work related respiratory symptoms and pulmonary function tests observed among construction and sanitary workers of Thoothukudi. International Journal of 
PharmTech Research. 4(3) (pp 12661273)

[5] Mofidi, A., Tompa, E., Jung, Y., Song, C., Jardine, K., Arrandale, V., Tenkate, T., Davies, H., Demers, P. (2019). Silica exposure and health effects a 30-year old impact analysis of best practices for silica dust exposure reduction in construction: cost, benefits and hrql. Occupational and Environmental Medicine 76(1)

[6] Fadrilan-Camacho, V.F., Quizon, R.R., Diaz, D.V., Manaloto, A.P. (2016). Challenges in the development of a medical surveillance system for pneumoconiosis and other asbestos- related diseases in the Philippines. Department of Environmental and

Occupational health: University of the Philippines Manila, 47(4) (pp. 822832)

[7] Mohner, M., Pohrt, Gellissen, J. (2017). Occupational exposure to respirable crystalline silica and chronic nonmalignant renal disease: systematic review and meta-analysis. International archives of occupational health, 90(7) (pp. 555-574)

[8] Stewart, R. (2019). Controlling and increasing compliance for the issue of respirable crystalline silica in the construction industry.

DOI: 10.13140/RG.2.2.30536.67844

[9] Diaz, D.V. (2009). Asbestos related disease in the philippines: the lung center of the philippines asbestos screening program. Acta Medica Philippina, 43(3)

[10] Granadilos, N., Parafina, M. (2020). Assessment of occupational safety and health hazards exposure of workers in small-scale gold mining in the Phillipines. International Labour Organization, Philippines

[11] Flanagan, M., Seixas, N., Majar, M., Camp, J., Morgan, M. (2003). Silica dust exposure during selected construction activities. AIHA Journal, 64(3) (pp 319-328)

[12] Barnes, H., Goh, N., Leong, T., Hoy, R. (2019). Silica-associated lung disease: An old-world exposure in modern industries. Respirology, 24(12) (pp. 1165-1175) 